\title{
Research on the Interactive Promotion Mechanism of Urban Parks and Leisure Sports
}

\author{
Fan Zhang \\ Department of Police Skills and Tactics, Nanjing Forest Police College \\ Sports Science postdoctoral programme, Nanjing Normal University \\ Nanjing 210023, China \\ zhangfan@nfpc.edu.cn
}

\begin{abstract}
In this paper, methods of documentation, field investigation, etc. are utilized to study the interactive relationship between urban parks and regional le is ure sports development in combination with the theory of urban leisure function. In order to better promote the interaction between fitness activities with space environment, the following viewpoint are drawn: under the background of le isure sports development, during urban parks construction, it should consider the "green \& ecological" planning of space, give priority to daily leisure needs of regional residents, actively introduce creative, globalized le isure sports functional areas, and enhance the cohesion of le isure culture in urban parks.
\end{abstract}

Keywords—urban park; leisure sports; interaction mechanism; promotion mechanism

\section{INTRODUCTION}

City is the symbol of human civilization and the unique gregarious space formed by the evolution of human civilization over thousands of years. In Athens Charter, leisure is one main function of city. In the 12th Five-Year Plan, the development of leisure sports first entered the national planning; and leisure sports played an important role in urban design, management and public services. Urban park is the public living space of city; the development of leisure sports has promoted the quality of city; the General Administration of Sports put forward the concept of "park-sports \& sports-parks" during "12th FiveYear Plan" and extended the transformation and planning of sports parks into construction of urban green space in "13th Five-Year Plan". Therefore, the study on interactive relationship between urban parks and development of urban leisure sports has certain theoretical and practical significance for the optimization and promotion of urban parks as well as the expansion and integration of spatial layout for urban leisure sport.

\section{OVERVIEW OF URBAN PARKS AND LEISURE SPORTS}

Urban function shows varied contents with the development of cities in different periods. Generally speaking, urban function is the provision of products and services that meet needs of urban residents for survival and development. Park is a new urban configuration. The word "Park" first

This work was supported in part by the Project of China Postdoctoral Science Foundation under Grant 2017M611849, in part by the Project of the Fundamental Research Funds for the Central Universities under Gran LGZD201805, in part by the 13th Five-Year plan project of Jiangsu Education Science under Grant C-c/2018/01/11, in part by Jiangsu Qing Lan Project under Grant 2017, and in part by Pre-research project of Nanjing Forest police College under Grant LGY201603 , and in part by Nanjing Forest police College Teaching Reform Project under Grant ZD18104. originated from the West in the nineteenth Century. The facilities and functions of urban parks are the main concerns in defining urban parks currently. Some scholars have summed up their main functions as follows: publicity, leisure, greenness, convenience and openness. Leisure sport is a kind of sports activities that people use their leisure time to achieve the purpose of entertaining body and mind, improving life quality and perfecting themselves according to their own hobbies and needs. The urban leisure function can be simply summarized as the sum of products and services provided by the city to meet the leisure needs of local residents and foreign tourists. Specific urban leisure functions also include the urban leisure node composed of elements e.g. activities, supporting facilities, service management, human environment and organizational management as well as the nature, function and utility of urban leisure management and human resource planning that meet the material and spiritual needs of audience during the process of aggregation, differentiation and optimal allocation of material, information and energy. The main content of urban park activity system is that the park exercisers use the park facilities and space to carry out collective or individual outdoor activities for health. It is the main form of carrier to maintain and promote national leisure sports.

\section{RELATIONSHIP BETWEEN URBAN PARKS AND LEISURE SPORTS DEVELOPMENT}

\section{A. Urban parks promote the development of leisure sports}

1) Urban parks expand the activities space of urban leisure sports: Rational behavior theory holds that behavior intention determines individual participation behavior. In 2016, China's urbanization level has reached $57.4 \%$, a large number of population influx caused the issues e.g. acceleration of life pace and compression of living space [1]. During process of urbanization, leisure sports are also developed rapidly. The lack of leisure sports space limits the predictive power of rational behavior theory and affects individual participation. As the main urban leisure space, the urban park alleviates the deficiency of the attached urban leisure space. As a public open sports area, urban parks have both the general characteristics of wide distribution and diversity of activities, facility simplicity, etc., which create an irreplaceable humanized leisure space. Sports park is a leisure sports space that takes leisure sports as the theme, combines ecological environment with 
leisure sports and has standard sports facilities; it belongs to the aerobic sports park with perfect combination of natural ecology and sports. Urban sports parks require that there should not be less than 8 sports facilities. It not only meets public needs for leisure and fitness, but also provides necessary places for urban leisure sports events.

2) Urban parks meet the basic needs for urban leisure sports: The post-modernization theory advocates that leisure sports should be oriented by human needs. Compared with the developed countries such as the US, Japan and Germany, China pays more attention to the planning and construction of competitive, large-scale and high-grade facilities in urban public sports facilities. The sports center of China, which was actively invested, with not high practicality, low openness and high maintenance cost, causes that the phenomenon of serious shortage of per capita public leisure sports facilities in China has not been effectively alleviated [2]. However, China has not yet issued construction and management standards of independent system for the construction of communitybased sports centers. Although the areas of sports venues and facilities in urban parks are not large as sports center, the leisure items in parks have certain migration. The decentralized layout can increase the universality of leisure sports activities. A variety of sports facilities, multiregional, multi-dimensional sports venues and pleasant sports environment can satisfy residents' needs for daily leisure exercise. By virtue of the natural environment, fishing, outing, fitness running and other leisure activities also meet the sports needs of consumers at different levels. Cultural exchange is one basic need of human beings. In urban parks, ball games, chess and card games, dance, martial arts and other leisure sports activities often attract many tourists to stop and watch. The active and relaxed atmosphere of park induces people's viewing behavior. The construction of urban parks with theme of leisure sports is more closely integrated with urban residents' pursuit of higher quality leisure life on sports needs based on the rapid development of national sports.

3) Urban parks create a beautiful environment for urban leisure sports: Everyone has the subjective need to pursue beauty. Cities are the concentrated areas of air pollution. The construction intention of urban parks originated from the expectation of urban residents for beautiful environment [3]. Urban Park combines green and humanities, which not only improves the ecological environment of city, but also serves as an important carrier of urban residents' leisure life. Studies have shown that creating a good artificial environment is conducive to improving the participation of leisure sports. From the perspective of psychology, green space provides virtuous circle for leisure sports and brings positive emotions. The scarcity theory hypothesis advocates sustainable development and puts forward that the future leisure sports should better promote the harmonious development of man and nature and create high-quality life and development pattern. The layout of urban parks not only focuses on the benefit of leisure function, but also takes into account the aesthetic feeling of art, the coordination of design of ecological plants with the changes of seasons, clear hierarchy, highlights the design of human details in public facilities such as walkways, lights, signs and seats; while satisfying the appreciation, it should also improve the service function of auxiliary functional area.

\section{B. Leisure sports promote the construction of urban parks}

1) Leisure sports guide renewal and upgrading of urban parks: Naturalness is one basic attribute of urban parks; and leisure sports is the return of natural attributes of human activities. With the development of urbanization, urban living space has gradually changed from productive function oriented to living demand oriented [4]. "Livable" has become the key criterion to judge the urban living environment. High-quality urban residents' planning of public space, the extension of consumption space and the grasp of living space have become the direction of demand evolution in this era. In early years, the focus of urban park design was mainly to ensure the visual effect of environment, but there was a lack of consideration for the function and efficiency. Urban parks mainly provide leisure services for human. The development of leisure sports helps urban parks to renew their own humanistic contents, reform the contents that are not in harmony with leisure life in order to meet the leisure needs of urban residents. Leisure city requires that leisure activities can participate in a wide range of types of urban life, a variety of leisure facilities and human services, and promote the development of diverse features for a livable, humane, characteristic and harmonious city. This also requires urban parks that, as the main carrier of urban leisure functions, under the premise of meeting the residents' leisure needs, should also be people-oriented with diversified development and enhance the core functions of public services in future urban parks.

2) Leisure sports promote planning and construction of urban parks: Owens's second nationally growing habitation pattern aims to take infrastructure as a "bait" to guide the population in a given region to transfer to a suitable location. However, in the past few decades, urban parks lacked humanistic planning in site selection or layout. Leisure sports, as a healthy and sustainable way of life, guide the orderly development of society and provide a useful way of interaction for interpersonal communication and harmonious social relations. However, there is a huge gap between China's sports facilities and resources with those of the US and Japan. According to interrelated data, the target of $1.5 \mathrm{~m}^{2}$ is less than one tenth of the current corresponding value in the US and one twelfth of that in Japan. Compared to developed countries, there is little difference in per capita park green areas in China, but the gap of per capita sports area exceeds 15 times, it can be seen that the value of many parks and green space resources has not been fully excavated. 
3) Leisure sports ensure the stability of urban parks: Regional theory holds that, in order to enlarge the coverage of public service facilities, the location layout must refer to the distribution of population in order to maximize the utility. Leisure sports advocate a positive, healthy and orderly lifestyle, which makes up for the imbalance of material and life in the urbanized life. Tourist groups in urban parks are mainly local residents. According to the feedback mechanism of system, leisure sports activities attract residents to park for leisure activities. When the number of people increases gradually, the environmental carrying capacity of urban parks and the public service efficiency will be reduced [5,6]. When the environmental carrying capacity reaches saturation, the number of leisure people will no longer increase but show s downward trend, then form a new dynamic balance. In this process, the content and structure of leisure sports activities are relatively stable and updated synchronously with the park environment, which makes the layout structure more harmonious and orderly; the leisure group structure is gradually improved, the scale of group activities is gradually expanded, and the degree of organization shifts from low to advanced, and eventually to regularization and networking. The space-time and ecology of urban parks are relatively fixed with the group leisure sports activities. The leisure sports chain can involve several system structures and lead the ecosystem to be relatively stable. Therefore, urban leisure sports ensure the regularity and stability of urban parks.

IV. FACTORS THAT SHOULD BE CONSIDERED IN DEVELOPING URBAN PARKS IN CONTEXT OF LEISURE SPORTS

\section{A. Emphasizing the "proticity" of space planning}

In the early years, there were fewer facilities in urban parks, and the standard of some sports venues was not high. Urban parks are ultimately provided for citizens, and the development goal of leisure cities is to further meet the high-quality living needs of urban residents; positioning leisure sports as city label is an advanced form of urban development. While satisfying certain fitness needs, green and natural landscape and multi-cultural function settings allow citizens to experience the pleasure of leisure, feel the beauty of returning to nature, dispel the too urbanized abruptness feeling, and truly achieve recreational purposes. Leisure sports parks are different from ordinary squares or plazas. Compared with the closed and monotonous gymnasium, the construction planning of urban leisure sports park mainly considers the integration of human landscape and leisure activity space, as well as the organic combination of indoor and outdoor fitness exercise with leisure recreation.In consideration of benefits, the renewal of urban parks should replace a large number of demolition work by dredging, retain the original leisure sports function, pay attention to the greening, functional and service transformation of land, and construct the urban green lung system with diversified landscape, stable growth and distinct primary and secondary levels as far as possible.

\section{B. Giving priority to leisure needs of regional residents}

China's sports venues focus more on the planning of "one site, two halls", but less on the allocation of daily sports fitness facilities; it is difficult to alleviate the problem of insufficient leisure sports space in cities. The service object of urban parks should be urban residents; venues and facilities should not be dedicated to the training and activities for high-level competitive competitions. Therefore, the planning and construction of venues and setting of sports events should also fully consider the daily leisure usage outside the competition, and meet the needs for leisure sports activities of different age groups from children to the elderly and different population. In addition to ball sports activities, the proportion of people with low exercise intensity activities such as "wandering" is relatively high in the recreational activities of urban parks. Simple and interesting recreational sports areas e.g. national fitness routes can be added to the existing parks in denselyspaced areas. In order to meet residents' needs for daily recreational sports activities, it can build new green ecological sports theme park, carry out a reasonable spatial layout and build a fitness walkway in the planning region of Urban New Area.

\section{Leisure sports activities should be diversified}

In the early years, the street park in old area was usually rebuilt from square to small park, which mainly contained landscape with too single function, and lacked rich cultural life to promote urban space exchange. The regional urban sports parks have large areas and focus on creating natural environment. However, the stadium composition is still dominated by natatorium and ball fields. The common allocations of urban sports parks in many developed countries e.g. extreme sports venues, camping areas, fishing areas, expanding sports venues and bicycle paths are relatively rare [7]. There is also lack of corresponding social guidance institutions and staffing. Building the urbanized fitness space and leisure experience can be gradually promoted from the region. The combination of national fitness with leisure culture enables the sports activities that can be carried out in urban parks to have more opportunities to contact with the global, entertaining and contemporary sports functional space besides the traditional popular sports; actively-planned outdoor sports facilities and space allow the city and leisure to return to nature and keep pace with the development of leisure sports in the world.

\section{CONCLUSION}

Urban parks combine many functions and elements e.g. ecology, society and economy. The rise of leisure sports makes the demand for construction of leisure sports places increase continuously. Different from the sports centers for various large-scale sports events, the functions and elements of urban parks are closely related to the promotion of human leisure sports development. Urban leisure sports park is an important place to enjoy the material environment, strengthen the communication between different social strata and enjoy the leisure sports life. During the planning and construction of urban park, the leisure sports function settings should be fully 
considered; and the cultural connotation and functional value of leisure sports should be combined with the open space and green ecological landscape of urban parks so as to promote the transformation of urban parks from passive ornamental space to comprehensive public service space.

\section{ACKNOWLEDGMENT}

I want to take this chance to thanks to Postdoctoral tutor-Wang Zhu-ying, a full professor of Nanjing Normal University. In the process of composing this paper, she gives me many academic and constructive advices, and helps me to correct my paper. Except these, she also gave me the opportunity to do my teaching practice. At the same time, I would like to appreciate my doctoral adviser, who gives me useful knowledge and information in this paper. He is Wang Chang-sheng. At last, I am very grateful of my dear friends, Yang Hai-cheng, Zhang Hui, who offered me the confidence and discuss with me about my paper. Of course, I do need to thanks my tennis friend, Jiang Qin-hua, Zhou Ai-ming, Shi Xiang-qun, et al, my mother, He Zu-ying, my father, Zhang Ben-yong, because of their warm care I can grow up well.

\section{REFERENCES}

[1] XU Xiu-yu, "study on characters of leisure supply and demand of urban parks - - a case of guangzhou," Yunnan Geographic Environment Research, vol. 25, pp. 69-75, June 2013. (In Chinese)

[2] ZHU Ji-yuan, XU Jie, ZHAO Jun, "A research on the status quo of urban residents' exercising in park," Liaoning Sport Science and Technology, vol. 36, pp. 28-31, January 2014. (In Chinese)

[3] ZHANG Da-chao, LI Min, "Studies on Evaluation Index System of Public Sports Facilities Development Level in China," China Sport Science, vol. 32, pp. 3-23, July 2013. (In Chinese)

[4] SONG Tienan, "Form of Sports Leisure Space in City in China from the Analysis Theory of Space in City," Journal of Shenyang Sport University, vol. 34, pp. 6-11, December 2015. (In Chinese)

[5] You Songhui, Qin Haiquan, He Chenjue, et al., "Interactive Relationship between Sports Leisure Industry and City Development,” Journal of shanghai physical eduction institute, vol. 35, pp. 58-62, April 2011. (In Chinese)

[6] HU Ying, LI Cui-xia, "Investigation and Analysis of Leisure Sports in a Park f rom Diachronic and Ecological Points of View,” China Sport Science, vol. 35, pp. 16-28, August 2015. (In Chinese)

[7] JIN Yin-ri, YAO Song-ping, JIANG Zong-yue, "The Empirical Research on Structure and Formation of Urban Leisure Sports Business District," Journal of shanghai physical education institute, vol. 35, pp. 37-40, December 2012. (In Chinese) 